\title{
Haemorrhagic versus non haemorrhagic ascites in cirrhosis: Their relationship and impact on prognosis of liver cirrhosis
}

\author{
Iftikhar Haider Naqvi' ${ }^{1}$ Khalid Mahmood ${ }^{2}$, Abu Talib ${ }^{3}$
}

\begin{abstract}
Objectives: To evaluate the impact of haemorrhagic ascites on prognosis of patients with advance cirrhosis, this study was further aimed to assess the relationship between haemorrhagic ascites and advance cirrhosis and its effect on prognosis.

Methods: Eight hundred and thirty-eight patients having liver cirrhosis with ascites were analyzed retrospectively (over three years) while segregated into two groups haemorrhagic and non haemorrhagic ascites. Patient outcome variables were identified among both groups and independent predictors for survival were analyzed. Kaplan-Meier survival estimates determined survival rate comparison between groups.

Results: Haemorrhagic ascites was detected in (26.6\%) patients. Spontaneous haemorrhagic ascites $(79 \%)$ was the main cause of haemorrhagic ascites followed by hepatocellular carcinoma $(14 \%)$ and iatrogenic (7.6\%).Spontaneous bacterial peritonitis and acute kidney injury were statistically significant $(p=0.0001$, 0.0001 ) among groups. Overall mortality at year three was higher (83\%) in haemorrhagic ascites group. Survival among both groups (haemorrhagic versus non haemorrhagic) at one month, one year and three year was found to be significant $(p=0.000,0.000$ and 0.000$)$.

Conclusion: Haemorrhagic ascites impact overall survival with more mortality in comparison to non haemorrhagic ascites. Haemorrhagic ascites was an independent predictor of survival. Haemorrhagic ascites is possibly considered another predictor of survival among advance cirrhosis.
\end{abstract}

KEYWORDS: Ascites, Hemorrhagic, Cirrhosis, Portal hypertension, Spontaneous bacterial peritonitis.

doi: https://doi.org/10.12669/pjms.36.4.2075

How to cite this:

Naqvi IH, Mahmood K, Talib A. Haemorrhagic versus non haemorrhagic ascites in cirrhosis: Their relationship and impact on prognosis of liver cirrhosis. Pak J Med Sci. 2020;36(4):603-608. doi: https://doi.org/10.12669/pjms.36.4.2075

This is an Open Access article distributed under the terms of the Creative Commons Attribution License (http://creativecommons.org/licenses/by/3.0), which permits unrestricted use, distribution, and reproduction in any medium, provided the original work is properly cited.

\section{INTRODUCTION}

Cirrhosis is an end-stage liver disease having reported global prevalence of $4.5 \%$ to $9.5 \% .^{1,2}$ Cirrhosis of liver with its well-known complications, contributes significantly to overall mortality worldwide.

\footnotetext{
1. Dr. Iftikhar Haider Naqvi, FCPS

2. Prof. Khalid Mahmood, FCPS, FRCP (Edin), FRCP (Glasgow)

3. Prof. Abu Talib, FCPS, FRCP (Glasgow).

1-3: Department of Medicine,

Dow University of Health Sciences, Karachi, Pakistan.

Correspondence:

Dr. Iftikhar Haider Naqvi, FCPS.

Associate Professor, Medical Unit-1

Dow University of Health Sciences, Karachi, Pakistan.

E-mail: drihnaqvi@gmail.com

* Received for Publication:

December 9, 2019

* Corrected and Edited:

February 22, 2020

* Accepted for Publication:

February 25, 2020
}

Ascites being most frequent complication of cirrhosis of liver is also the commonest reason for hospital admission in cirrhotic patients. ${ }^{3}$ Presence of ascites profoundly impacts survival of cirrhotic patients as evidenced by reported mortality of $15 \%$ and $44 \%$ within one and five year respectively. ${ }^{4}$ Hemorrhagic ascites defined as red blood cell (RBC) count greater than $10,000 / \mathrm{mm}^{3}$ against normal RBC count $(<1000 / \mathrm{mm} 3)$ in ascitic fluid, is less frequent yet challenging complication among cirrhotic patients with ascites. ${ }^{5}$ Haemorrhagic ascites has 5\% reported prevalence among cirrhotics with atypical features in comparison to usual ascites. ${ }^{6}$

Haemorrhagic ascites with its enhancing impact on morbidity and mortality of cirrhotic patients in relation to hepatocellular carcinoma, ruptured varices and trauma has been elaborated in earlier studies. ${ }^{6,7}$ The importance of routine ascitic fluid analysis in hospitalized patients with cirrhosis 
focuses on measuring white blood cell count to exclude spontaneous bacterial peritonitis. However, ascitic fluid analysis reveals RBC count $<50,000 \mathrm{~mm}^{3}$ (between 10,000 to $50,000 / \mathrm{mm} 3$ ) among reasonable number of cirrhotic patients. The clinical utility of identifying haemorrhagic ascites, thus its impact on patients' survival with advance liver disease is still undetermined on large scale. However, as consistently observed the patients with haemorrhagic ascites have a poor outcome and survival among patients with advanced cirrhosis of liver. Apart from two large retrospective studies, ${ }^{8,9}$ most reported data on haemorrhagic ascites were actually related to hemoperitoneum (RBCs before $>50,000 / \mathrm{mm} 3$ ) in non-critical clinical setting and described in small case series and case reports.7,10,11

Cirrhosis related Pakistani health statistics indicate huge increase in mortality from 10,324 $(6,129-16,651)$ to $31,373(16,325-61,028)$ within last three decades (from 1980 to 2010). ${ }^{12}$ The overall agestandardized mortality rate (per 100,000) in cirrhosis is $21.7 \%$ to $27.5 \%$ in Pakistan. ${ }^{12}$ Among well-known complications contributing to mortality in cirrhotics, data on haemorrhagic ascites is limited. This study was aimed to assess the relationship between haemorrhagic ascites and advance cirrhosis as well as its effect on overall impact on prognosis.

\section{METHODS}

Retrospective data of 838 patients having confirmed cirrhosis of liver with ascites, were analyzed from January 2015 to December 2018 over three years. All patients aged $\geq 18$ to 65 years of either sex having ascites who had at least one ascitic tap were enrolled at Medical Unit-1, Civil Hospital Karachi and Dow University of Health Sciences. Patients having malignancy, who had left against medical advice and with incomplete information, were excluded from study. Patients were segregated into two groups one haemorrhagic ascites where other was non haemorrhagic ascites group. Details of cirrhosis, its complications like hepatic encephalopathy (HE), hematemesis, portal vein thrombosis (PVT), hepatocellular carcinoma (HCC) and patients stay in high dependency unit were recorded. Investigations both base line and related to cirrhosis like haemogram, liver chemistries, International normalized ratio, creatinine, viral markers (HbsAg and Anti-HCV), ultra sound with splenic size and endoscopic data (Varices and their degree) were retrieved. Scores related to prognostication like Child Turcot Pugh score (CTP) and Model of End stage liver disease (MELD) score and death records of patients were also obtained from data.
Cirrhosis: Cirrhosis of liver was confirmed on patient's history related to cirrhosis, clinical features (ascites, hepatic encephalopathy and esophageal varices), imaging (ultrasonography and computed tomography showing small shrunken liver) and biochemical parameters. Histopathology also confirmed cirrhosis wherever required. ${ }^{12}$

Hepatic encephalopathy: Hepatic encephalopathy and its various grades were labeled according to West Haven Criteria and graded 1-4. ${ }^{13}$

Acute Kidney injury: Acute Kidney injury (AKI) is determined where ascites persists in cirrhosis even after withholding all diuretics and adequate fluid resuscitation whereas serum creatinine remained $>1.5 \mathrm{mg} / \mathrm{dL} .{ }^{14}$

Haemorrhagic ascites: Haemorrhagic ascites is defined when ascitic fluid contains $>10,000 / \mathrm{mm}^{3}$ RBC as by earlier published data on the subject. ${ }^{8,9}$

Non Haemorrhagic ascites: Non haemorrhagic ascites is defined when ascitic fluid contains < $10,000 / \mathrm{mm}^{3} \mathrm{RBC}$ which is well in accordance to the earlier published data on the subject. ${ }^{8,9}$

Causes of haemorrhagic ascites:

1. Hepatocellular carcinoma (HCC) related

When advance imaging shows hemoperitoneum secondarily to HCC, including direct bleeding from mass, localized hematoma adjacent to mass, a liver mass $\geq 5 \mathrm{~cm}$ or mass of any size close to the surface $(1 \mathrm{~cm}){ }^{14,15}$

Iatrogenic hemorrhagic ascites:

Hemoperitoneum detected in the patient after paracentesis, either diagnostic or therapeutic or liver biopsy.

Spontaneous hemorrhagic ascites:

Hemoperitoneum where no cause is identified. ${ }^{16,17}$

Statistical Analyses: Data were analyzed through Statistical analyses SPSS software version 21 (SPSS Inc.; Chicago, Illinois, USA). Standard deviation and mean were used for descriptive analyses. Patients' outcome variables were identified between haemorrhagic and non-haemorrhagic groups by univariate analysis and investigated through Chi square, Fisher exact, Student $t$ and Mann-Whitney $\mathrm{U}$ tests, as required. Independent predictors for variables were analyzed by multivariate regression. Survival rate comparisons between both groups were determined using Kaplan-Meier survival estimates. To infer statistical significance A 5\% type-I error level was used.

\section{RESULTS}

Demographic, clinical and biochemical profile: Out of 838 cirrhotic patients analyzed, haemorrhagic ascites was detected in $223(26.6 \%)$ patients whereas 
Table-I: Comparison of demographic, clinical and biochemical parameters between hemorrhagic versus non hemorrhagic groups.

\begin{tabular}{|c|c|c|c|c|c|c|}
\hline & & \multicolumn{2}{|c|}{$\begin{array}{l}\text { Hemorrhagic Ascites } \\
(n=223)\end{array}$} & \multicolumn{2}{|c|}{$\begin{array}{l}\text { Non-Hemorrhagic Ascites } \\
\qquad(n=615)\end{array}$} & \multirow{2}{*}{$P$ value } \\
\hline & & $n$ & $\%$ & $n$ & $\%$ & \\
\hline Age & & \multicolumn{2}{|c|}{$44.8 \pm 14.5$} & \multicolumn{2}{|c|}{$49 \pm 13.4$} & 0.000 \\
\hline \multirow{4}{*}{ Gender } & Female & 86 & 39 & 232 & 38 & \multirow{4}{*}{0.443} \\
\hline & Male & 137 & 61 & 383 & 62 & \\
\hline & $\mathrm{AIH}$ & 11 & 5 & 32 & 5 & \\
\hline & Alcoholic Hepatitis & 4 & 2 & 11 & 2 & \\
\hline \multirow[t]{6}{*}{ Etiology } & Cryptogenic & 2 & 1 & 7 & 1 & \multirow{5}{*}{0.1} \\
\hline & Hemochromatosis & 2 & 1 & 6 & 1 & \\
\hline & $\mathrm{HBV}$ & 59 & 26 & 159 & 26 & \\
\hline & $\mathrm{HCV}$ & 136 & 61 & 374 & 61 & \\
\hline & Wilson Disease & 9 & 4 & 26 & 4 & \\
\hline & Diffuse abdominal pain & 65 & $29 \%$ & 129 & $21 \%$ & 0.016 \\
\hline Clinical features & Abdominal distension & 118 & $53 \%$ & 141 & $23 \%$ & 0.000 \\
\hline \multirow{4}{*}{ Stages of CTP } & Unconsciousness & 98 & $44 \%$ & 153 & $25 \%$ & 0.000 \\
\hline & CTP-A & 7 & 3 & 19 & 3 & \multirow{3}{*}{0.06} \\
\hline & СТР-B & 78 & 35 & 271 & 44 & \\
\hline & СТР-C & 138 & 62 & 325 & 53 & \\
\hline \multirow[t]{10}{*}{ Biochemical parameter } & & \multicolumn{2}{|c|}{ Mean $\pm S D$} & \multicolumn{2}{|c|}{ Mean $\pm S D$} & \\
\hline & ALT iu/ml & \multicolumn{2}{|c|}{$68 \pm 6.9$} & \multicolumn{2}{|c|}{$55.5 \pm 6.2$} & 0.01 \\
\hline & Creatinine mg/dl) & \multicolumn{2}{|c|}{$1.5 \pm 0.8$} & \multicolumn{2}{|c|}{$1.28 \pm 0.7$} & 0.000 \\
\hline & Bilirubin mg/dL & \multicolumn{2}{|c|}{$6.1 \pm 0.3$} & \multicolumn{2}{|c|}{$4.8 \pm 0.3$} & 0.000 \\
\hline & INR & \multicolumn{2}{|c|}{$1.8 \pm 0.4$} & \multicolumn{2}{|c|}{$1.5 \pm 0.3$} & 0.000 \\
\hline & MELD Score & \multicolumn{2}{|c|}{$23.1 \pm 9$} & \multicolumn{2}{|c|}{$19.2 \pm 6$} & 0.000 \\
\hline & CTP Score & \multicolumn{2}{|c|}{$10 \pm 1.7$} & \multicolumn{2}{|c|}{$9.1 \pm 1$} & 0.000 \\
\hline & $\mathrm{Hb} \% \mathrm{gm} / \mathrm{dL}$ & \multicolumn{2}{|c|}{$7.3 \pm 1.2$} & \multicolumn{2}{|c|}{$8.7 \pm 1.1$} & 0.000 \\
\hline & $\mathrm{WBC} / \mathrm{mm} 3$ & \multicolumn{2}{|c|}{$8 \pm 1.3$} & \multicolumn{2}{|c|}{$6.4 \pm 3.4$} & 0.000 \\
\hline & Platelets/mm3 & \multicolumn{2}{|c|}{$121 \pm 29$} & \multicolumn{2}{|c|}{$127 \pm 49$} & 0.062 \\
\hline
\end{tabular}

non haemorrhagic ascites was found in 615 (73.3\%). Age, gender, aetiology of cirrhosis and its severity among groups are highlighted in Table-I. Liver chemistries like ALT, bilirubin, albumin and INR among both groups with their statistical significance ( $\mathrm{p}$ values of $0.01, .0001,0.0001$ and 0.000 ) have shown in Table-I. Severe liver disease as evidenced by MELD and CTP score was found in the patients with haemorrhagic ascites where mean CTP score was $10 \pm 1.7$ and 9.1 $\pm 1 \quad(p=0.000)$ and MELD score was $23.1 \pm 9$ and $19.2 \pm 6(p=0.000)$ in both groups respectively as shown in Table-I.

Portal hypertension indices and complications: Spleen had a mean size of $16 \pm 3 \mathrm{~cm}$ in the haemorrhagic ascites group and $15 \pm 3 \mathrm{~cm}$ in controls with statistical significance $(p=0.0001)$. Stage of ascites with their frequency among both groups have statistical significance $(p=0.18)$ in Table-II. Degree of varices with their frequency among the groups having statistical significance $(p=0.0001)$ Table-II. Various complications of cirrhosis among both groups showed only SBP and AKI to be statistically significant $(p=0.0001,0.0001)$ as shown in Table-II.

Causes of haemorrhagic ascites: Spontaneous haemorrhagic ascites 176 (79\%) was the main cause of haemorrhagic ascites followed by HCC 30(14\%) and iatrogenic $17(7.6 \%)$ in this study. 
Iftikhar Haider Naqvi et al.

Table-II: Comparison of Indices of portal hypertension and complications between hemorrhagic versus non hemorrhagic ascites groups.

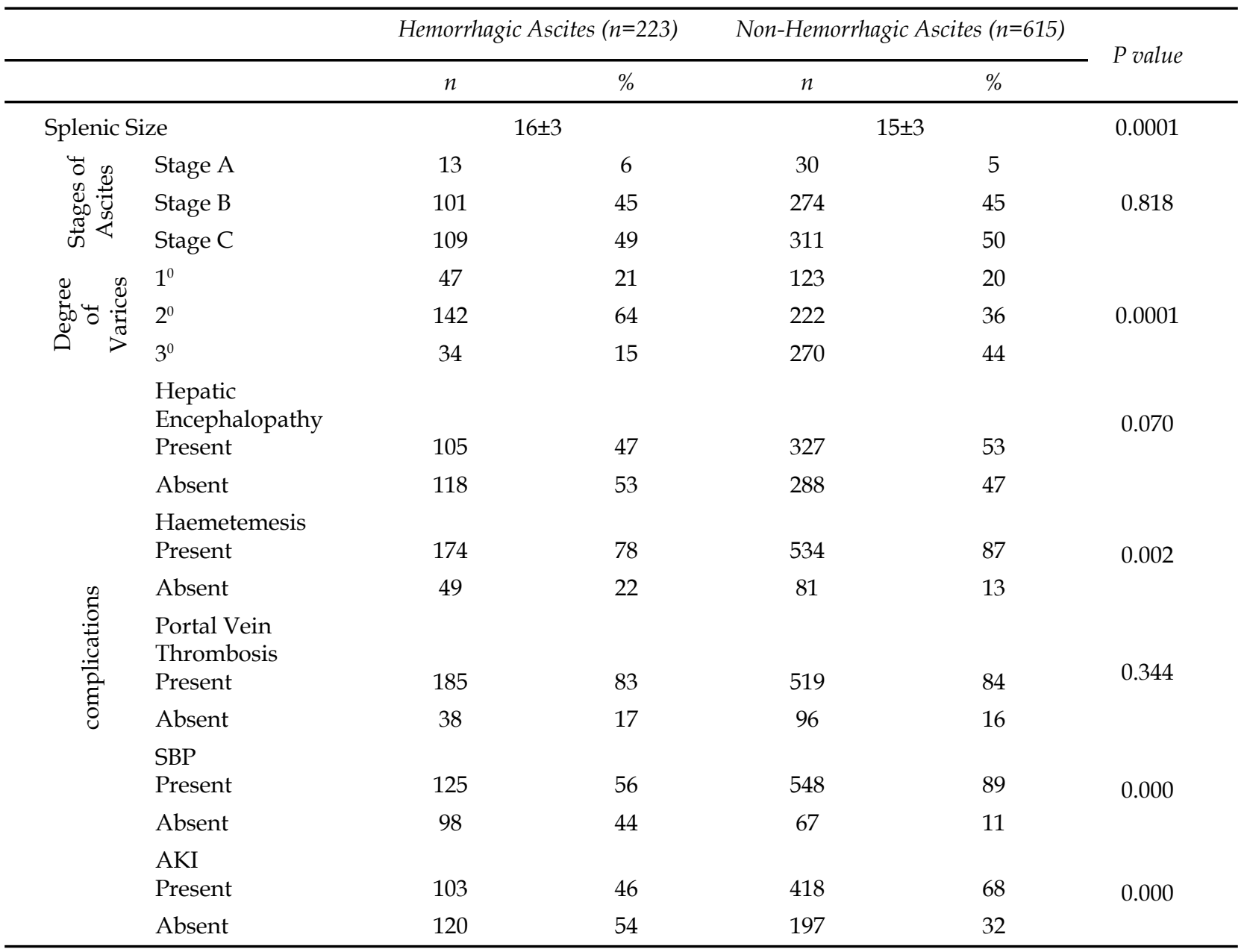

Survival analysis: Overall mortality at year 3 was $83 \%$ in comparison to $70 \%$ among non haemorrhagic ascites. From the haemorrhagic ascitic group 71\% survived one month, $17 \%$ survived 1 year and $13 \%$ patients survived 3 year with survival probability estimates $(0.73,0.18$ and 0.135$)$ respectively. Whereas, from non haemorrhagic ascites group $87 \%$ survived one month, $50 \%$ survived 1 year and $27 \%$ patients survived 3 year with survival probability estimates $(0.87,0.51$ and 0.28$)$ respectively was found significant $(\mathrm{p}=0.000,0.000$ and 0.000) as shown in Fig-1.

Predictors of mortality: Among various parameters only haemorrhagic ascites (Odd ratio $=0.45, \mathrm{P}=0.000$, $\mathrm{CI}=0.31-0.734)$, hepatic encephalopathy (Odd ratio=0.347, $\mathrm{P}=0.000, \mathrm{CI}=0.214-0.563)$ and $\mathrm{SBP}$ (Odd ratio 6.07, $\mathrm{p}=0.000, \mathrm{CI}=2.6-14.2$ ) qualified as independent predictors of mortality. Table-III Ascitic $R B C^{\prime} S$ range: Patients of haemorrhagic ascites were grouped on the basis of ascitic RBC'S count where $16(7.3 \%)$ patients had ascitic RBC'S count $>50,000 / \mathrm{mm} 3$ while majority had ascitic

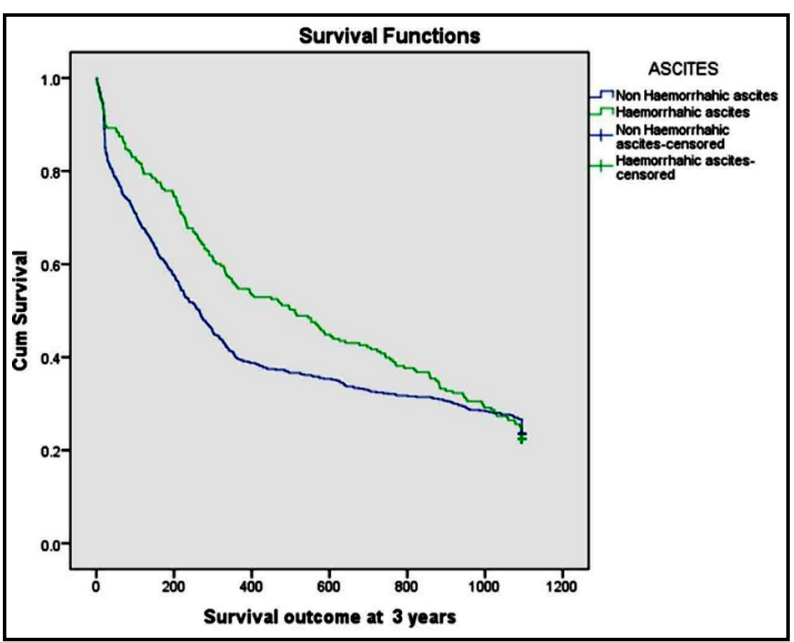

Fig.1: Survival outcome of haemorrhagic and non haemorrhagic ascites at 3 years. 
Table-III: Determination of independent predictors of mortality (multinomial logistic regression analysis).

\begin{tabular}{lccc}
\hline Variable & Odds Ratio & P Value & Confidence Interval \\
\hline Age & 1.00 & 0.216 & $0.997-1.021$ \\
Gender & 1.143 & 0.449 & $0.809-1.614$ \\
Haemorrhagic ascites & 0.45 & 0.000 & $0.31-0.734$ \\
MELD Score & 0.994 & 0.645 & $0.969-1.019$ \\
Hepatic encephalopathy & 0.347 & 0.000 & $0.214-0.563$ \\
Hematemesis & 0.499 & 0.263 & $0.147-1.686$ \\
Portal vein Thrombosis & 0.659 & 0.405 & $0.247-1.757$ \\
SBP & 6.07 & 0.000 & $2.6-14.2$ \\
AKI & 1.685 & 0.07 & $0.959-2.961$ \\
\hline
\end{tabular}

RBC'S count between 10,000/mm3 - 50,000/mm3. Statistical significance is not evidenced as $\mathrm{p}$ values shown $(0.73,0.60,0.32$ and 0.80$)$. Table-IV.

\section{DISCUSSION}

Haemorrhagic ascites was present in $223(26.6 \%)$ in this study whereas earlier studies ${ }^{8,9}$ have $25 \%$ and $35.5 \%$ patients with haemorrhagic ascites. Most patients in this study had viral related (Chronic $\mathrm{HCV}$ and $\mathrm{HBV}$ ) as the cause of cirrhosis whereas study by Yildiz et al. ${ }^{9}$ showed chronic HBV followed by HCV mainly causing cirrhosis. Urrangana et al. ${ }^{8}$ showed alcohol as a cause of cirrhosis followed by chronic HCV and HBV.

Hyponatremia, raised creatinine, hypotension and advance severity of liver disease (High CTP and MELD score) are well established poor prognostic indicators among patients with liver cirrhosis., ${ }^{419,20}$ Spontaneous hemorrhagic ascites was found incidentally among cirrhotics presents without signs of haemorrhage (hypotension, tachycardia and syncope). Earlier studies ${ }^{6,10}$ suggest that hemorrhagic ascites may indicate poor prognosis among cirrhotics due to increased risk of AKI, HE and high mortality. Two possible mechanisms related to development of spontaneous haemorrhagic ascites have been proposed. ${ }^{10}$ First proposed mechanism is of intra-abdominal bleeding from an organ or a small peritoneal vessel, or a varix,${ }^{13}$ whereas second is related to raised portal or splenic pressure causing diapedesis of erythrocytes within peritoneum.

Increased splenic size and higher degree of varices in patients with haemorrhagic ascites in this study validates the role of raised portal or splenic pressure as a cause of haemorrhagic ascites. This is similar to the earlier studies.,10 Complications like haemetemesis, AKI and SBP occur frequently with haemorrhagic ascites as compared to non haemorrhagic ascites. Earlier studies ${ }^{8,9}$ have also endorsed SBP and AKI as frequently reported problem with haemorrhagic ascites whereas $\mathrm{HE}$ was also found significantly.

This study showed high mortality rate at 1 month, 1 year and 3 year among patients with haemorrhagic ascites like large earlier published studies., ${ }^{8,9}$ This study has tested various determinants like Haemorrhagic ascites, HE, portal vein thrombosis, SBP as an independent predictor of mortality among patient of cirrhosis with ascites and found haemorrhagic ascites, SBP and HE as an independent predictor of mortality. Yildiz et al. ${ }^{9}$ had shown haemorrhagic ascites along with hepatorenal syndrome and HCC as an independent predictor for mortality in large cohort at Turkey. Urrunaga et al. ${ }^{8}$ in their study had also shown similar results where multilogistic regression determined haemorrhagic

Table-IV: Comparison of complication of cirrhosis among subgroups of haemorrhagic ascites.

\begin{tabular}{lccc}
\hline Complications of cirrhosis & $\begin{array}{c}\text { Haemorrhagic ascites }(\text { RBC'S }> \\
50,000 / m m 3 ~ N(\%)\end{array}$ & $\left.\begin{array}{c}\text { Non haemorrhagic ascites }(\text { RBC'S } \\
10,000-50,000 / \text { mm3 })\end{array}\right)$ & $P$ Value \\
\hline HDU admission & $10(65 \%)$ & $139(67 \%)$ & 0.73 \\
AKI & $07(43.7 \%)$ & $109(52.6 \%)$ & 0.60 \\
SBP & $09(55 \%)$ & $87(42 \%)$ & 0.32 \\
Hepatic encephalopathy & $09(55 \%)$ & $108(52 \%)$ & 0.80 \\
\hline
\end{tabular}


ascites as an independent predictor of mortality along with HCC and high MELD score.

Current study also tested range of ascitic RBC'S count among haemorrhagic ascites either having $10,000-50,000 / \mathrm{mm} 3$ or $>50,000 / \mathrm{mm} 3$ as earlier determined by Yildiz et al. ${ }^{9}$ and found same results. This further validates earlier study that 10,000 / $\mathrm{mm} 3-50,000 / \mathrm{mm} 3$ ascitic RBC'S count can be considered for haemorrhagic ascites. Among types of haemorrhagic ascites spontaneous haemorrhage was the most common cause in this study with abdominal distension. Haemorrhagic ascites presenting with worsening ascites and shock is always related to ruptured varices or HCC have been reported in about $0.5 \%$ patient. ${ }^{6,10,21}$ This study had shown 07 (3.1\%) patients who died with HCC related haemorrhage which is quite high as compare to earlier study. ${ }^{8}$

Limitations of the study: It was retrospective design and missing of iatrogenic hemorrhagic ascites at first paracentesis. However, imploring experienced physicians in paracentesis, making it ultrasound guided, including first paracentesis value and omission of two and $3^{\text {rd }}$ paracentesis values have overcome the problem. Even though ascitic tap related hemorrhage or bleeding complications of peritoneum is very rare $(0.01 \%)$ like earlier studies. ${ }^{23,24}$

\section{CONCLUSION}

Haemorrhagic ascites impact overall survival with more mortality in comparison to non haemorrhagic ascites. Haemorrhagic ascites was an independent predictor of survival. Haemorrhagic ascites is possibly considered another predictor of survival among advance cirrhosis.

\section{Grant Support \& Financial Disclosures: None.}

\section{REFERENCE}

1. Graudal N, Leth P, Mårbjerg L, Galløe AM. Characteristics of cirrhosis undiagnosed during life: a comparative analysis of 73 undiagnosed cases and 149 diagnosed cases of cirrhosis, detected in 4929 consecutive autopsies. J Intern Med. 1991;230:165-171. doi: 10.1111/j.1365-2796.1991.tb00425.x

2. Lim YS, Kim WR. The global impact of hepatic fibrosis and endstage liver disease. Clin Liver Dis. 2008;12:733-746. doi: 10.1016/j. cld.2008.07.007

3. Runyon BA; AASLD Practice Guidelines Committee. Management of adult patients with ascites due update. Hepatol. 2009;49:2087-107. doi: 10.1002/hep. 22853

4. Guevara M, Gines P. Prognosis in patients with cirrhosis In: Gines P, Arroyo V, Rodes J, Schrier RW, editors. Ascites and renal dysfunction in liver disease: pathogenesis, diagnosis and treatment. Malden: Blackwell. 2005;23:260-270.

5. McGibbon A, Chen GI, Peltekian KM, van Zanten SV. An evidencebased manual for abdominal paracentesis. Dig Dis Sci. 2007;52:33073315. doi: 10.1007/s10620-007-9805-5.
6. Akriviadis EA. Hemoperitoneum in patients with ascites. Am J Gastroenterol. 1997;92:567-575.

7. Mallory A, Schaefer J. Complications of diagnostic paracentesis JAMA. 1978;239:628-630. doi: 10.1001/jama.1978.03280340048020

8. Urrunaga NH, Singal AG, Cuthbert JA, Rockey DC. Hemorrhagic ascites. Clinical presentation and outcomes in patients with cirrhosis. J Hepatol. 2013;58(6):1113-1118. doi: 10.1016/j.jhep.2013.01.015

9. Yildiz H, Akdogan M, Suna N, Oztas E, Kuzu UB, Bilge Z, et al. Cirrhosis with ascites: Is the presence of hemorrhagic ascites an indicator of poor prognosis? Turk J Gastroenterol. 2016;27(4):349353. doi: 10.5152 /tig.2016.160042.

10. DeSitter L, Rector WG. The significance of bloody ascites in patients with cirrhosis. Am J Gastroenterol. 1984;79:136-138.

11. Liebowitz HR. Hazards of abdominal paracentesis in the cirrhotic patient. NY State J Med 1962;62:2223-2229.

12. Naqvi I, Talib A, Mahmood K, Abidi R, Zehra Rizvi S. The ability of the new ALBI scoring in predicting mortality, complications and prognostic comparison among cirrhotics. Gastroenterology Review/ Przegląd Gastroenterologiczny. 2019. doi: 10.5114/pg.2019.83872

13. Ferenci P, Lockwood A, Mullen K, Tarter R, Weissenborn K, Blei AT. Hepatic encephalopathy-definition, nomenclature, diagnosis, and quantification: final reportof the working party at the 11th world congresses of gastroenterology, Vienna, 1998. Hepatol. 2002;35:716721. doi: $10.1053 /$ jhep. 2002.31250

14. Mehta RL, Kellum JA, Shah SV, Molitoris BA, Ronco C, Warnock DG, et al. Acute kidney injury network:report of an initiative to improve outcomes in acute kidney injury. Cri Care. 2007;11:R31. doi: $10.1186 / \operatorname{cc} 5713$

15. Clarkston W, Icciardi M, Kirkpatrick S. Acute hemoperitoneumfrom rupture of a hepatocellular carcinoma. J Clin Gastroenterol. 1988;10:221-225. doi: 10.1097/00004836-198804000-00025.

16. Tarantino L, Sordelli I, Calise F, Ripa C, Perrotta M, Sperlongano P. Prognosis of patients with spontaneous rupture of hepatocellular carcinoma in cirrhosis. Uptades Surg. 2011;63:25-30. doi: 10.1007/ s13304-010-0041-8

17. Pache I, B. ilodeau M. Severe haemorrhage following abdomina paracentesis for ascites in patients with liver disease. Aliment Pharmacol Ther. 2005;21:525-529. doi: 10.1111/j.13652036.2005.02387.x

18. MartinetO,ReisED,MosimannF. Delayedhemoperitoneumfollowing large volume paracentesis in a patient with cirrhosis andascites. Dig Dis Sci. 2000;45:357-358. doi: 10.1023/A:1005424929241

19. Llach J, Ginès P, Arroyo V, Rimola A, Titó L, Badalamenti S, et al Prognostic value of arterial pressure, endogenous vasoactive systems and renal function in cirrhoticpatients admitted to the hospital for the treatment of ascites. Gastroenterol. 1988;94:482-487. doi: 10.1016/00165085(88)90441-6

20. Salpeter SR, Luo EJ, Malter DS, Stuart B. Systematic review of noncancer presentations with a median survival of 6 months or less. Am J Med. 2012;125:512.e1. doi: 10.1016/j.amjmed.2011.07.028

21. Norton ID, Andrews JC, Kamath PS. Management of ectopic varices. Hepatol. 1998;28:1154-1158. doi: 10.1002/hep.510280434

22. Ma YJ, Chen EQ, Lu JJ, Tan MZ, Tang H. Hemoperitoneum in cirrhoticpatients without abdominal trauma or tumor. Hepatobiliary Pancreat Dis Int. 2011;10:644-648. doi: 10.1016/ S1499-3872(11)60109-4

23. Runyon BA. Paracentesis of ascitic fluid: A safe procedure. Arch Intern Med 1986;146:2259-2261. doi: 10.1001/archinte.1986.00360230201029

24. McVay PA, Toy PT. Lack of increased bleeding after paracentesis and thoracocentesis in patients with mild coagulation abnormalities. Transfusion. 1991;13:164-171. doi: 10.1046/j.15372995.1991.31291142949.x

\section{Authors Contribution:}

IHN: Conceived, designed and did statistical analysis \& editing of manuscript.

IHN \& AT: Did data collection and manuscript writing.

KM: Did review and final approval of manuscript. 